\title{
Endo-gastric Teratoma - A Rare Cause of Upper GI Bleeding in an Infant!
}

\author{
Shivani Deswal ${ }^{1} \cdot$ Vivek Dewan $^{1} \cdot$ Arvind Ahuja $^{2} \cdot$ Shikha Singh $^{1} \cdot$ Rahul Tiotia $^{1} \cdot$ K Vani Narayani $^{1} \cdot$ Saba Anwar $^{1}$
}

Received: 6 June 2019 / Accepted: 4 October 2019 / Published online: 11 November 2019

(C) Dr. K C Chaudhuri Foundation 2019

To the Editor: Teratomas are germ cell tumors uncommonly encountered in the pediatric age group. Gastric teratomas comprise of $<1 \%$ of all teratomas. Endo-gastric teratomas constitute $<30 \%$ of all gastric teratomas [1]. We describe a case of endo-gastric teratoma in a seven-mo-old boy who presented with recurrent episodes of melena for past 1 mo and two episodes of altered blood in vomitus. He had received two packed red blood cell transfusions. There was no history of jaundice, abdominal lump, drugs, trauma or bleeding from other sites. At presentation, baby had mild pallor with normal systemic examination. Laboratory studies showed Hemoglobin $9.3 \mathrm{~g} / \mathrm{dl}$, platelet count $360,000 / \mathrm{mm}^{3}$, International Normalized Ratio -1.03 and normal liver function tests. Ultrasound abdomen was normal. Urgent endoscopy revealed a well-defined pedunculated fleshy mass $3 \times 2 \times$ $1 \mathrm{~cm}$ on the greater curvature of stomach just below the fundus. Rest of the examination was normal. Preoperative biopsy showed few fragments of hyaline cartilage suggesting possibility of gastric teratoma. Abdominal Computed Tomography with oral contrast revealed heterogeneously enhancing polypoidal mass lesion of size $3.3 \times 3.4 \times 2.8 \mathrm{~cm}$ in the stomach with its base towards greater curvature and projecting into the lumen of the stomach. There was no evidence of any other obvious polypoidal growth. Alpha fetoprotein $(13.37 \mathrm{ng} / \mathrm{ml})$ and Beta HCG levels $(<1.20 \mathrm{mIU} / \mathrm{ml})$ were reported normal for age. He underwent wide local excision with $2 \mathrm{~cm}$ tumor free margin. Post-operative course was uneventful. Histopathology revealed polypoidal tissue lined by stratified squamous epithelium along with adnexal structures. There

Shivani Deswal

shivanipaeds@gmail.com

1 Department of Pediatrics, ABVIMS \& Dr.Ram Manohar Lohia Hospital, New Delhi 110001 Delhi, India

2 Department of Pathology, ABVIMS \& Dr. Ram Manohar Lohia Hospital, 110001 New Delhi Delhi, India was focal intestinal epithelium, respiratory epithelium along with gastric epithelium. Neuroepithelium was not identified in the multiple sections examined. A diagnosis of mature teratoma was confirmed.

Less than 120 cases of gastric teratomas have been reported so far [2]. Exogastric variety presents with lump abdomen, vomiting or respiratory distress. Hematemesis and melena point towards endogastric variety or combined exo and endogastric component [3]. Most gastric teratomas are mature and have excellent prognosis. Incomplete resection is the main reason for the recurrence [4]. Monitoring of AFP and beta HCG is of significance where chemotherapy is recommended in immature teratomas [5].

\section{Compliance with Ethical Standards}

Conflict of Interest None.

\section{References}

1. Saleem M, Mirza B, Talat N, Sharif M. Gastric teratoma: our 17 year experience. J Pediatr Surg. 2018;53:234-6.

2. Hasan R, Monappa V, Kumar S, Kumar V. Large gastric teratoma: a rare intra-abdominal mass of infancy. Oman Med J. 2016;31:231-4.

3. Aihole JS, Babu MN, Jadhav V, Javaregowda D. Gastric teratoma: an unusual presentation and location. Indian J Med Paediatr Oncol. 2017;38:563-5.

4. Gangopadhyay AN, Pandit SK, Sinha A. Gastric teratoma-review of literature. Indian J Pediatr. 1992;59:541-4.

5. Singh S, Rawat J, Ahmed I. Immature extragastric teratoma of infancy: a rare tumour with review of the literature. BMJ Case Rep. 2011. https://doi.org/10.1136/bcr.12.2010.3674.

Publisher's Note Springer Nature remains neutral with regard to jurisdictional claims in published maps and institutional affiliations. 